\title{
Bevacizumab and radiotherapy for the treatment of glioblastoma: brothers in arms or unholy alliance?
}

\author{
Maximilian Niyazi ${ }^{1,2}$, Patrick N. Harter ${ }^{2,3}$, Elke Hattingen ${ }^{4}$, Maya Rottler ${ }^{1,2}$, Louisa \\ von Baumgarten ${ }^{5}$, Martin Proescholdt ${ }^{6}$, Claus Belka ${ }^{1,2}$, Kirsten Lauber ${ }^{1,2}$ and Michel \\ Mittelbronn ${ }^{2,3}$ \\ 1 Department of Radiation Oncology, University of Munich, Germany \\ ${ }^{2}$ German Cancer Consortium (DKTK) and German Cancer Research Center (DKFZ), Heidelberg, Germany \\ ${ }^{3}$ Institute of Neurology (Edinger Institute), Goethe University, Frankfurt, Germany \\ ${ }^{4}$ Department of Neuroradiology, University Hospital Bonn, Bonn, Germany \\ ${ }^{5}$ Department of Neurology, University of Munich, Munich, Germany \\ ${ }^{6}$ Department of Neurosurgery, University Hospital Regensburg, Regensburg, Germany \\ Correspondence to: Kirsten Lauber, email: kirsten.lauber@med.uni-muenchen.de
}

Keywords: glioma, radiotherapy, bevacizumab, angiogenesis, VEGF

Received: August 19, $2015 \quad$ Accepted: October 13, $2015 \quad$ Published: November 13, 2015

This is an open-access article distributed under the terms of the Creative Commons Attribution License, which permits unrestricted use, distribution, and reproduction in any medium, provided the original author and source are credited.

\section{ABSTRACT}

Glioblastoma (GBM) represents the most frequent primary brain tumor in adults and carries a dismal prognosis despite aggressive, multimodal treatment regimens involving maximal resection, radiochemotherapy, and maintenance chemotherapy. Histologically, GBMs are characterized by a high degree of VEGF-mediated vascular proliferation. In consequence, new targeted anti-angiogenic therapies, such as the monoclonal anti-VEGF-A antibody bevacizumab, have proven effective in attenuating tumor (neo)angiogenesis and were shown to possess therapeutic activity in several phase II trials. However, the role of bevacizumab in the context of multimodal therapy approaches appears to be rather complex. This review will give insights into current concepts, limitations, and controversies regarding the molecular mechanisms and the clinical benefits of bevacizumab treatment in combination with radio(chemo) therapy - particularly in face of the results of recent phase III trials, which failed to demonstrate convincing improvements in overall survival (OS).

\section{BACKGROUND}

GBMs are highly vascularized tumors that critically depend on the generation of tumor-associated blood vessels $[1,2]$. They are characterized by a dense network of highly disorganized, tortuous, large-diameter vessels with increased basement membrane thickness [3, 4]. The pathological tumor vasculature is functionally abnormal and leads to increased vessel permeability, vasogenic edema and hemorrhages [5]. The resulting rich capillary network may contribute to rapid tumor growth and poor prognosis. As the vasculature in GBMs is characterized by a highly disorganized vessel architecture, this may also limit the efficacy of radioand chemotherapy by compromising blood flow, thereby enhancing tumor hypoxia and impairing oxygen-mediated, irradiation-induced DNA damage as well as the delivery of chemotherapeutics $[2,6]$. Among multiple factors controlling the complex process of angiogenesis, vascular endothelial growth factor (VEGF) and its associated signaling cascade are considered to be of central importance [5, 7]. Glioma cells are a major source of VEGF, and high levels of VEGF have been reported to correlate with high-grade malignancy and poor prognosis $[8,9]$. Radiotherapy $(\mathrm{RT})$ is a mainstay of GBM treatment and is known to dramatically increase VEGF expression by transactivating factors, including NFKB and p53 [10]. Accordingly, it was speculated that targeting VEGF might enhance the efficacy of RT. Upon inhibition of VEGF signaling the downstream effects (temporary increase in perfusion, decrease in interstitial edema/hypertension as well as permeability) should all support the efficacy of 
concomitant RT [5, 11].

Currently, the most prominent VEGF targeting drug is bevacizumab (BEV), a recombinant humanized monoclonal antibody that binds to human VEGF-A. Several groups have investigated the use of BEV with an already proven efficacy in metastatic colon, breast, and lung cancer for patients with recurrent malignant gliomas $[12,13]$. BEV was also tested in combination with RT in recurrent GBM [14], or as upfront treatment together with RT and concomitant temozolomide (TMZ) administration $[15,16]$. It proved to be a safe and feasible treatment option. The mode of action was attributed to scavenging mechanisms, which counteract irradiationinduced VEGF secretion by inactivating VEGF [17], thus resulting in consecutive advantageous effects, including reduction of vascular permeability and edema, improved oxygenation as well as reduction of radiation necrosis $[5$, 18]. Furthermore, several phase II trials have documented the efficacy of anti-VEGF therapies either alone or in combination with irinotecan [19-25], etoposide [26, 27], nitrosourea [28], or other agents [29, 30]. However, the initially reported promising response rates to BEV treatment might be at least in part - attributed to imaging limitations resulting from decelerated neoangiogenesis and reduced vascular permeability, thus leading to an apparent but debatable reduction in the contrast-enhancing tumor volume [31, 32].

Recent prospective phase III trials (AVAglio \& RTOG 0825) were designed to prove the efficacy of TMZbased radiochemotherapy in combination with BEV as first-line therapy for GBM. While the RTOG 0825 trial failed to show significant benefits in terms of progressionfree (PFS) and overall survival (OS), the AVAglio study demonstrated a significant prolongation of PFS by 4.4 months in the BEV arm. However, this PFS benefit did not translate into an improvement in OS [33, 34]. In line with this, several preclinical and clinical studies raised the concern that BEV treatment might induce a more invasive tumor phenotype, thereby potentially limiting the efficacy of radiation therapy due to the stimulation of tumor cell emigration out of the RT field [35-38]. Moreover, an increased incidence of neurocognitive side effects was reported for the combination of RT and BEV treatment and is currently attributed to VEGF's role as neuroprotector [39]. Overall, due to the general limitations of the existing phase II/III trials, it remains controversial whether the initial preclinical rationale to combine anti-VEGF treatment and RT has to be regarded as corroborated or disproven [33,34], and this is not the only important question in the field, which waits to be resolved. Here, we aim at providing an overview of the current knowledge, hypotheses, and discussions about the molecular mechanisms underlying the effects of BEV treatment in combination with irradiation and their clinical implications for the treatment of GBM patients.

\section{THERAPEUTIC EFFECTS OF BEV AND TREATMENT RESISTANCE IN PRECLINICAL GLIOMA MODELS}

Anti-angiogenic therapy targeting VEGF or its receptors is considered to impact on glioma growth through several mechanisms, some of which are only poorly understood [40]. The initial hypothesis was that anti-angiogenic therapy prunes tumor vessels and reduces tumor blood perfusion, thereby starving the tumor of oxygen and essential nutrients, resulting in reduced tumor growth [41]. However, accumulating evidence indicates that one therapeutic effect of antiVEGF treatment derives from transient normalization of the functionally abnormal tumor vasculature, leading to a reduction in edema and improved tumor oxygenation [42]. Preclinical studies suggest that this time window of normalization is important with regard to the schedule of combination therapies. Winkler et al. hypothesized that blockade of VEGF receptor 2 (VEGFR2) creates a "normalization window". Within this time window, the combination with RT provides the best results of tumor control, originating from a temporary increase in tumor oxygenation, which is well known to enhance irradiationinduced DNA damage and thus irradiation-induced tumor cell death. Mechanistically, vascular normalization stimulated by VEGFR2 blockade emerges from increased pericyte coverage of brain tumor vessels via up-regulation of Angiopoietin 1 (Ang1) and degradation of the pathologically thick basement membrane via activation of matrix metalloproteases (MMPs) [43]. Dings et al. described similar findings for BEV treatment and VEGF inhibition [44]. Interestingly, a similar normalization effect has been described for radiotherapy itself or in combination with other treatment modalities $[45,46]$. However, although the data on vascular normalization appear very promising, so far they remain limited to preclinical and extracerebral models.

In principle, the term "vascular normalization" might be misleading as some tortuous, largediameter vessels will not immediately disappear upon administration of BEV (if not already removed by prior resection). But there is another reason, which supports the notion that RT and BEV treatment can act synergistically. The term "window of opportunity" as introduced by Jain et al. appears to describe the physiological effects that can be observed during RT and BEV treatment more precisely [5]. It does not seem to be an anatomically evaluable effect with less "disturbed" vessels, which turn "normal", but rather a functional one. Normalization upon anti-VEGF treatment appears to be due to higher perfusion rates, less vascular permeability, less interstitial edema and hypertension, as well as less subsequent hypoxic burden. This, in turn, may immediately enhance the efficacy of RT and is from a kinetic point of view a short-term effect $[11,47]$. Importantly, the potential adverse effects of long- 
term anti-VEGF treatment should not be confused with these obviously positive short-term effects as proven by preclinical trials $[11,43]$.

Apart from its impact on tumor vessel architecture and function, it remains controversial whether or not $\mathrm{BEV}$ possesses direct anti-tumor activity, and to date it is unknown if there is a threshold dose or dose-response relationship. We established an orthotopic mouse glioma model, which allowed us to simultaneously study the kinetics of morphological and functional vascular changes, tumor growth, and viability of individual tumor cells during the course of anti-VEGF therapy within the same microscopic tumor region in real-time. Notably, regression of gliomas occurred independently of vascular regression, suggesting that high doses of $\mathrm{BEV}$ have direct anti-cancer efficacy in vivo [48]. In line with this, a recent study provided evidence that gliomas expressing VEGFR2 comprise an aggressive subgroup of tumors, which develop resistance against TMZ and BEV treatment very early [49]. On the contrary, other preclinical studies could not reproduce the beneficial effects of anti-VEGF treatment on tumor growth control and improved survival in mice bearing orthotopically transplanted or autochthonous gliomas [50]. In this report, the described increase in progression-free survival times (PFS) in humans was interpreted as a decrease in vasogenic edema by a stabilization of tumor-associated brain microvessels and by a still controversially discussed increase in invasiveness, which in turn might potentially reduce the diagnosable local tumor mass, e.g. in eloquent CNS areas. Although VEGFR2 is traditionally regarded as an endothelial cell protein, there is accumulating evidence suggesting that VEGFRs may be expressed by cancer cells [49]. Hamerlik et al. proposed that VEGFR2 is preferentially expressed on the cell surface of CD133 human glioma stem-like cells, whose viability, selfrenewal, and tumorigenicity rely at least in part on signaling through the VEGF-VEGFR2-Neuropilin-1 (NRP1) axis. It was hypothesized that a limited impact of BEV-mediated VEGF blockage may reflect ongoing autocrine signaling through VEGF-VEGFR2-NRP1 [51]. If these findings can be directly transferred to human patients is highly questionable, since we and others could not corroborate the suitability of CD133 as a cancer stem cell marker in human gliomas [52].

\section{THE METABOLIC SWITCH INDUCED BY ANTI-ANGIOGENIC TREATMENT AND ITS RELEVANCE FOR THE EFFICACY OF RADIOTHERAPY}

$\mathrm{BEV}$ treatment leads to a considerable change in the composition of metabolites in the CNS as assessed by neuroimaging. However, most aspects of the changes in the cellular and metabolic composition after anti-angiogenic treatment still remain to be defined. Meanwhile it is well acknowledged among physicians and scientists in the neurooncological field that BEVtreated gliomas reveal a more hypoxic, more glycolytic, and/or more invasive phenotype, although only limited experimental evidence supporting this issue is available [53]. This recycled statement mainly relies on cell culture or preclinical animal models. Detailed analyses were provided by Keunen and colleagues who characterized the effects of anti-VEGF treatment in intracranial glioblastoma xenografts [54]. In this study, a significant reduction in the cerebral blood flow and the amount of large and median-sized blood vessels upon anti-angiogenic treatment was associated with a dramatic increase in glioma cell invasion into the tumor-surrounding CNS. The tumor tissue became strongly hypoxic as reflected by an increase in lactate and alanine production paralleled by activation of hypoxia-inducible factor $1 \alpha$ (HIF $1 \alpha)$. These changes indicate that anti-angiogenic treatment shifts energy production in glioma cells predominantly towards anaerobic glycolysis - a finding, which is further corroborated by the fact that glioma cells display decreased numbers of mitochondria upon BEV treatment. The metabolic switch towards anaerobic glycolysis is most likely due to changes in the tumor vasculature, since direct exposition of isolated glioma cells to BEV did not induce considerable changes in the metabolic profile [55]. Yet, these results have to be interpreted with caution, since only one human glioma cell line was used. The lack of detailed information about a metabolic switch in human tissue inspired us to address this question in human glioma cells and tissue samples together with an international consortium of neurooncological colleagues [56]. As previously reported in animal models, also human glioma cells displayed increased lactate production accompanied by reduced levels of metabolites necessary for the functioning of the tricarboxylic acid cycle. Along this line, expression levels of glycolytic enzymes were elevated upon BEV treatment suggesting a switch towards anaerobic glycolytic metabolism. Immunohistochemical analyses of post-BEV resection or autopsy samples revealed increased lactate dehydrogenase-A (LDH-A) expression not only in perinecrotic areas where LDH-A expression is commonly seen in treatment-naive samples but also in large vital tumor parts or even in single glioma cells diffusely infiltrating the surrounding CNS tissue. All these findings clearly point towards a metabolic adaptation process, which is not related to clonal selection of glioma cell subsets. Meanwhile, in vivo imaging techniques supporting an intratumoral metabolic switch upon antiangiogenic treatment have been developed [57, 58].

In summary, there seems to be a discordant pattern: On the one hand, BEV treatment apparently enhances radiosensitivity by reducing tumor hypoxia during the vascular normalization phase, on the other hand a switch towards anaerobic glycolysis has convincingly 
been reported. It remains to be elucidated which of these mechanisms has higher relevance in clinical practice.

\section{THE CHANGING NEURORADIOLOGICAL FACE OF GLIOMAS UPON BEV- TREATMENT}

One of the major reasons for the negative regulatory votum against $\mathrm{BEV}$ in the first line therapy of GBM is the relative uncertainty of imaging criteria during BEV treatment. The discrepancy between PFS prolongation and lack of OS benefit was attributed to the reduced permeability of the blood brain barrier (BBB) leading to a delayed detection of tumor recurrence - a phenomenon termed pseudo-response. Already in very early studies applying BEV in the context of recurrent gliomas, more than $75 \%$ of the patients showed at least a partial neuroradiologically confirmed treatment response [59]. Surprisingly, with 27 weeks the OS was only marginally longer than the PFS pointing towards disease stabilizing and/or progression masking effects rather than sustained long-term anti-tumor activity. A significant association of radiographic responses and high VEGF expression levels was observed, even though patient survival was not prolonged [60]. Pioneering neuroradiological work on $\mathrm{BEV}$ treatment in gliomas reported a significant reduction in the edema-to-tumor volume and a relative decrease in necrotic areas [61]. We could show that the contrastenhancing tumor volume and edema declined significantly upon initiation of BEV treatment, whereas the noncontrast-enhancing tumor volume did initially not decrease but increased strikingly at progression [62]. However, these results should be interpreted with caution, since magnetic resonance (MR)-based differentiation between non-enhancing tumor volume and edema relies on signal intensities only. Other MR studies revealed that elementary MR parameters, such as the T1- and T2 relaxation times, can assess treatment response and also progressive tumor infiltration with higher sensitivity $[58,63,64]$. The relative cerebral blood volume (rCBV) has also been identified as an important neuroradiological parameter to predict the time to progression (TTP) in BEV-treated GBM patients [65]. In addition, we observed that T1-hyperintense lesions with diffusion restriction were positively associated with prolonged patient survival upon anti-angiogenic treatment $[66,67]$. Parallel computed tomography (CT) imaging suggested the presence of calcifications in BEV-treated GBMs, which could be confirmed by means of histological analyses [67]. Meanwhile it became evident that more than $50 \%$ of all GBM patients treated with BEV develop similar imaging alterations, which seem to be predictors of an anti-angiogenic treatment response. Although attempts to categorize neuroradiological progression under antiangiogenic treatment have been initiated, so far no official guidelines could be established [68].

In summary, the aforementioned novel neuroradiological findings, which are associated with anti-angiogenic therapy and have not been previously observed under standard radiochemotherapeutic regimens, fuel the still ongoing debate about pseudo-progression and/or pseudo-response [69]. This dilemma might best be resolved by detailed neuroimaging and neuropathological analyses in a setting allowing for kinetic correlation of MR changes and histopathology. Another option for the exclusion or confirmation of a pseudo-response after BEV treatment might be ${ }^{18} \mathrm{~F}$-fluoroethyl-1-tyrosine positron emission tomography ([ $\left.\left.{ }^{18} \mathrm{~F}\right] \mathrm{FET}-\mathrm{PET}\right)$. Several reports have described obvious characteristics following BEV treatment, but so far no data on combined modality approaches are available [70-72].

\section{CURRENT STATUS OF IRRADIATION AND ANTI-ANGIOGENIC TREATMENT: WILL THE CARDS BE RESHUFFLED?}

The treatment of malignant brain tumors has been subject to a variety of clinical studies combining RT with BEV with or without TMZ [73]. In 2014, the results of two large randomized trials on BEV in primary GBM treatment have been published. In the AVAglio trial, combined radiochemotherapy with TMZ according to the Stupp regimen (EORTC 26981 - 22981 NCIC CE3 trial) [74, 75] was compared to the same regimen in combination with $\mathrm{BEV}$. The median PFS in the BEV group exceeded that in the placebo group (10.6 months vs. 6.2 months; HR 0.64; $95 \%$ CI 0.55 to $0.74, p<0.001)$. Yet, the overall survival (OS) was not significantly different between both groups (HR 0.88; 95\% CI 0.76 to $1.02, \mathrm{p}=0.10$ ), but improved maintenance of baseline quality of life and performance status were observed with BEV. Of note, the rate of adverse events was also higher in the BEV arm [33]. In the same issue of the New England Journal of Medicine, the results of the similarly designed RTOG 0825 trial were published. There was no significant difference in median OS between both treatment arms (15.7 or 16.1 months, respectively; HR for death in the BEV group 1.13). The median PFS was longer in the BEV group (10.7 months vs. 7.3 months; HR 0.79), but the pre 7 specified significance level for PFS was not reached. In contrast to the AVAglio trial, where an improved quality of life was reported for the BEV group, the opposite if any change in the quality of life and a possible deterioration in neurocognitive performance was observed in the RTOG 0825 trial [34]. In summary, both phase III trials failed to show prolongation of OS by BEV-containing treatment regimens, whereas significant and marginally significant PFS benefits were described, and contradicting results were obtained when evaluating quality of life or neurocognition (no data within the AVAglio trial), respectively [33, 34].

The phase II GLARIUS trial explored the efficacy of BEV plus irinotecan compared to standard TMZ in the first-line radiochemotherapy of GBM patients with non- 
methylated O-6-methylguanine-DNA methyltransferase (MGMT) promoter. In the BEV/irinotecan arm, PFS was significantly prolonged from a median of 5.9 months (95\% CI 2.7-6.2 months) to 9.7 months (95\% CI 8.710.5 months, $\mathrm{p}=0.0004$; HR 0.56 , 95\% CI $0.4-0.79$ ). Nevertheless, no prolongation of the median OS and no improvement in the quality of life were observed [76]. In summary, two well-conducted randomized phase III studies and one phase II trial could not demonstrate significant $\mathrm{OS}$ benefits by adding $\mathrm{BEV}$ to standard radiochemotherapy for patients with newly diagnosed GBM.

One might come to discordant conclusions when considering the available clinical phase II/III results [33]. Apparently, there are improvements in terms of PFS, but these might derive from neuroradiological pseudoresponses. Moreover, the failure to show benefits in OS leaves little place for the notion of putative synergistic interactions between $\mathrm{BEV}$ and $\mathrm{RT}$ - at least in the context of radiochemotherapy. In contrast, the median OS in the BEV groups was clearly prolonged as compared to historical controls, and the substantial crossover, which has taken place within the trials and renders them statistically difficult to analyze, might account for the failure to reach the defined endpoint of OS prolongation. Therefore, longitudinal crossover correction analyses of the GLARIUS trial are currently in preparation, and the results are eagerly awaited. Given all these limitations, it currently remains unclear whether BEV administration in combination with radiochemotherapy can exert synergistic effects and clinical efficacy for the first line treatment of GBM patients. Clearly, treatment schedules as well as patient selection should be reassessed in order to derive more conclusive results in the future.

The decision of the EMA (European Medicines Agency) against $\mathrm{BEV}$ for the treatment of newly diagnosed GBM was based on the results of both RTOG 0825 and AVAglio. However, the observations of initial attempts to use BEV in recurrent glioma appear promising and inspired an ongoing second line chemotherapy trial (EORTC26101, BEV + lomustine), which might lead to the approval of $\mathrm{BEV}$ for the treatment of recurrent malignant glioma. This trial is based on the efficacy of $\mathrm{BEV}$ and lomustine within the BELOB phase II trial [77]. Accordingly, a reassessment in combination with RT might be possible in future.

\section{FUTURE DIRECTIONS}

We have learned from the treatment of high grade gliomas with BEV in both preclinical models and clinical settings that anti-angiogenic therapies considerably change tumorbiological properties, including vascularization and tumor cell metabolism. These effects can be clearly demonstrated by means of neuroradiological and neuro $\neg$ pathological analyses. Nevertheless, although the morphological and physiological changes in the tumor were associated with prolonged PFS in several phase II/III trials the OS remained virtually unchanged. Which are the putative reasons for this and how should they be addressed in the future?

\section{CRITICAL REASSESSMENT OF THE VESSEL-NORMALIZATION CONCEPT AND ANTI-TUMORAL EFFECTS OF BEV IN THE CONTEXT OF COMBINATORY TREATMENT STRATEGIES}

The concept of vascular normalization implies increased pericyte coverage as well as reduced basement membrane thickness of tumor vessels, and led to the hypothesis that these changes could favor tumor oxygenation, which in turn would improve treatment effects and thus patient survival $[43,78]$. Already in the pioneering work of Winkler and colleagues the term "normalization window" was introduced reflecting that an optimal time window for RT in the context of antiangiogenic treatment does exist [43]. However, it appears highly challenging to fine-tune the best moment of vascular normalization for combined treatment modalities in the clinical routine. From a neuropathological perspective, it is also difficult to understand how large glomeruloid vascular structures, once they have been established in the glioblastoma micromilieu, should undergo a normalization process, which could be exploited by radiochemotherapeutic approaches. Moreover, our intravital microscopy study revealed that regression of gliomas during anti-angiogenic therapy can occur independently of vascular normalization, suggesting that the underlying molecular mechanisms are multifactorial and comprise more aspects than vascular normalization only [48]. Hence, it still remains to be determined in detail if and by which means anti-angiogenic treatment can set a favorable ground for radio- and/or chemotherapy. This is of pivotal importance, since combined modality approaches might also have negative additive effects. For both irradiation and anti-angiogenic therapy, experimental studies have shown enhanced glioma cell invasiveness, and RT can also affect the tumor vasculature [79-82]. Accordingly, future research should aim at deciphering the putative positive synergistic effects of anti-angiogenic treatment and RT and particularly also their potentially detrimental consequences for GBM patients as well as the underlying mechanisms.

\section{WHO PROFITS - WHO SUFFERS: ATTEMPTS OF PATIENT STRATIFICATION}

Despite encouraging results using anti-angiogenic therapy in GBM it appears that only a subset of patients experiences survival benefits when receiving BEV 
treatment, and striking differences in response rates and long-term tumor control have been observed. Biomarkers able to identify patients, who would specifically benefit from anti-angiogenic therapy in combination with radiochemotherapy still remain an unmet need not only in neurooncology $[83,84]$. In this regard, baseline levels and/or variation of numerous intratumoral or circulating candidate biomarkers have been extensively explored. However, so far their predictive values remain weak, and they could rarely be confirmed among different studies [85]. A recent report suggested that circulating levels of VEGF-A are prognostic for the outcome of metastatic colorectal, lung and renal cell cancer, but they were not predictive for BEV-based treatment benefits [86]. Elevated VEGF-expression in recurrent malignant gliomas as determined by IHC, however, was associated with increased response rates to BEV but did not predict survival, whereas high expression of carbonic anhydrase 9 (CA9) was related to poor survival outcome [60]. Yet, in the AVAglio trial pretreatment plasma concentrations of VEGF and sVEGF did not show significant associations with PFS or OS, respectively [87]. In the context of BEV-treatment for recurrent GBM, increased baseline numbers of $\mathrm{CD} 109^{+}$circulating endothelial cells (CECs) identified a subgroup of patients with longer PFS and OS, which also encompassed more long-term responders [88]. Additionally, high MMP2 plasma levels were reported to be associated with treatment response and survival in patients with recurrent GBM under BEV treatment but not under cytotoxic chemotherapy alone [89]. Further research and randomized clinical trials are clearly needed in order to evaluate the predictive power of these potential biomarkers in the future.

Molecular genetic advances have contributed to a better understanding of GBM pathophysiology and might have the potential for disease stratification. The most recent, clinically relevant classification has been provided by The Cancer Genome Atlas consortium (TCGA). On the basis of gene expression profiling with respect to p53, epidermal growth factor (EGFR), neurofibromin (NFI), platelet-derived growth factor alpha (PDGFRA) and isocitrate dehydrogenase 1 (IDH1) four distinct molecular subtypes of GBMs (proneural, neural, classical, and mesenchymal) were defined [90]. Importantly, clear differences in prognosis were observed for these molecular subtypes with proneural GBM exhibiting relatively favorable prognosis - a finding that had already been reported before $[90,91]$. Colman et al. further introduced a multigene predictor set of 9 genes associated with a mesenchymal (angiogenic) GBM phenotype and glioma stem cell markers, which appears to have considerable potential for optimizing GBM therapy and for identifying novel therapeutic approaches in order to specifically target GBMs that are refractory to standard therapy [92]. Hypothesizing that the marked differences in oncogenic and angiogenic drivers across distinct expression signatures might translate into differential responses to anti-VEGF therapy, patient stratification in the RTOG 0825 trial was dichotomized into favorable and unfavorable outcome based on this 9 -gene panel. However, no prospectively defined subgroup of patients exhibited selective survival benefits from the early administration of BEV [34]. Preliminary molecular subgroup analyses on the basis of a 10-gene predictor of mesenchymal-subtype-associated genes warrants further testing [93]. Pilot data from the AVAglio trial suggest that the proneural molecular GBM subtype (tumors with IDH mutations excluded) might respond better to BEV treatment than the other three molecular subtypes [94].

In summary, for both phase III trials considerable efforts have been undertaken to define patient subgroups who would particularly profit from BEV treatment plus radiochemotherapy. Different strategies were followed. Whereas the RTOG 0825 consortium started with the Colman signature and subsequently defined a 9-/10gene set of mesenchymal GBM [92], the AVAglio team employed subtyping according to Philipps and Verhaak and could show that for some GBM subgroups BEV treatment was effective, while for others detrimental effects could be observed $[90,94]$. So far, these subgroup analyses remain on an exploratory level, and the predictive significance of the molecular genetic signatures has to validated. Consequently, independent evaluation is planned within the GLARIUS cohort, and the results are awaited with great interest. Taken together, to date no GBM subtype has been identified to be "advantageous" when using radiochemotherapy plus BEV, and currently no reliable a priori evaluation does exist in order to determine whether or not a patient will profit from BEV therapy. Independent cross-trial confirmation of putative predictive biomarkers is lacking, and so their use in current clinical practice has to be discouraged [41]. Further efforts are required in order to examine the value of TCGA-based transcriptional classification as well as other putative biomarkers with the aim of increasing the likelihood of successful of anti-angiogenic treatment.

\section{IRRADIATION AND ANTI-ANGIOGENIC TREATMENT: BROTHERS IN ARMS OR UNHOLY ALLIANCE?}

The interaction between VEGF signaling and RT has been addressed in several preclinical studies [43, 95100]. Irradiation reportedly stimulates the upregulation of VEGF in different glioma cell lines and xenografts [17, 98], and interfering with VEGF signaling by neutralizing antibodies has been shown to enhance the anti-tumor effects of ionizing radiation more than additively [43, 95, 101]. Notably, scavenging VEGF with BEV increased the sensitivity of both tumor and endothelial cells to the cytotoxic effects of ionizing irradiation. Hence, improved tumor control in glioma xenografts by combined 
administration of BEV and RT was attributed to the abrogation of irradiation-induced VEGF signaling and better tumor oxygenation due to vascular normalization $[11,43]$.

The clinical efficacy of BEV application in combination with RT as assessed by PFS and OS is currently being extensively discussed. However, one aspect remains commonly disregarded in this context: The beneficial impact of BEV on attenuating radiation-induced cerebral necrosis. To our knowledge, there has been only one small prospective randomized trial addressing this issue, and it provided clear evidence for the successful treatment of radiogenic brain necrosis with BEV [102]. This is of particular interest, since dose escalation has been a relevant topic in the field of RT for GBM over years. It has never definitely been proven that a doseresponse-relationship above 60 Gy does exist, and there are different reasons why several clinical trials failed [103107]. Yet, the high frequency of local and/or in-field GBM recurrence renders insufficient local tumor control the most plausible explanation [108-110]. Tsien et al. showed in a phase I trial that gradual dose escalation up to $84 \mathrm{~Gy}$ is feasible with an acceptable risk of late central nervous system toxicity. Unfortunately, no data on concomitant TMZ administration are available, and overall patient numbers were small [111]. BEV treatment could be a valuable strategy in the context of dose escalation, since the induction of radiation necrosis in the brain is a major concern in this regard [112]. Administration of BEV could be utilized in order to counteract the onset and/or aggravation of radiogenic brain necrosis, and irradiation doses could be increased with the aim of improving local tumor control. The reasons why BEV can prevent radiation necrosis are poorly understood. Hypotheses range from a reduction in interstitial edema, a decrease in interstitial hypertension to a reduction in the permeability of leaky vasculature, and others. Notably, some of these also are supposed to underlie the wanted synergistic interactions with RT in terms of tumor control [18]. Individual case reports underscore the dramatic effects of BEV when treating symptomatic, radiation-induced cerebral necrosis $[113,114]$. Hence, it might be worth to consider increasing the irradiation dose to achieve improved tumor control and administering BEV for the protection of the normal brain parenchyma - at least on a very careful and caseby-case basis. In such aggressive treatment regimens, the potentially negative influences on neurocognition should always be payed attention to and need to be properly assessed.

The increased risk of radiation necrosis was an initial concern when the concept of re-irradiation of malignant glioma emerged. However, in recent years this treatment option has been adopted as safe and effective [115-121]. For recurrent malignant glioma, BEV was repeatedly used in combination with re-irradiation. One group tested the sequential administration of radiosurgery and BEV with favorable outcome [122]. Complementarily, Gutin and co-workers determined the safety and activity of RT and concomitant BEV treatment. Here, PFS after 6 months (PFS-6) reached 65\% for the GBM cohort [14]. In a previous retrospective study on 30 patients ( 20 being treated with BEV and 10 without BEV), we could show that PFS-6 within the BEV-treated group was $72 \%$, and OS was significantly prolonged [123]. In a second study with substantially longer follow-up and a higher patient numbers, the significant post-recurrence survival (PRS) benefit obtained by BEV application could be confirmed, and a low incidence of side-effects was observed [124]. Along these lines, there is an ongoing RTOG 1205 trial, which aims at evaluating improvements in OS for patients with recurrent GBM receiving BEV and re-irradiation as compared to patients receiving $\mathrm{BEV}$ alone. Other trials employing BEV and re-irradiation also provided favorable results [125-127].

One further concern about anti-angiogenic treatment in the context of RT is an increased stimulation of glioma cell migration and invasiveness. Results from preclinical studies have shown that (perivascular) invasion increases during anti-VEGF therapy and might thereby limit therapeutic efficacy [50, 128-130]. Tumor cells within the invasive margins of GBMs can escape anti-angiogenic therapy and local irradiation, because they can migrate into surrounding areas of normal brain parenchyma, which are located outside the irradiation field and whose intact blood-brain barrier prevents BEV from entering the tissue. However, these tumor cells have been predicted to be susceptible to irradiation-induced abrogation of clonogenic survival providing a further rationale for combining anti-angiogenic therapy with irradiation of the tumor surrounding margins, yet at lower doses [99, 131]. Initial clinical reports revealed that anti-VEGF therapies were associated with non-contrast-enhancing radiographic tumor progression, which was interpreted as an increase in tumor invasiveness [35]. Available clinical data, however, are very heterogeneous, and the major studies do not uniformly support the assumption that BEV treatment induces invasive growth at time of recurrence $[33,36,132$, 133]. If a more invasive GBM phenotype emerged during therapy, this should become obvious in a higher frequency of out-of-field recurrences due to increased tumor cell migration [134]. Although a numerically slightly higher rate of diffuse progressions was observed in the BEV arm of the AVAglio study, this did not significantly affect OS. However, the initial growth pattern (diffuse vs. non-diffuse) was per se prognostic. In patients who had non-diffuse tumors at baseline, median OS was 20.1 (BEV arm) and 18.4 months (standard arm), whereas for tumors with diffuse growth patterns at baseline, median OS was 15.6 (BEV arm) and 16.2 months (standard arm), respectively [38]. When examining the relapse patterns in patients with recurrent malignant glioma under BEV treatment in combination with re-irradiation, we observed 
mainly centrally located recurrences [135]. A second argument commonly listed when discussing the potential stimulation of glioma invasiveness under BEV treatment is that in view of improved PFS and equal OS in the BEV arms of AVAglio and RTOG 0825, post-PFS survival apparently is decreased in comparison to non-BEV treated patients. Yet, this issue is difficult to evaluate, since the relevant crossover rates within both trials render them statistically complex to analyze (31\% within the AVAglio trial, RTOG 0825 even higher). Crossover correction analyses are required in order to address this concern comprehensively.

Finally, a major caveat of BEV application in combination with RT in GBM remains: detrimental neurocognitive effects. Unfortunately, RTOG 0825 and AVAglio, do not provide conclusive results in this regard. From a physiological point of view, this hypothesis cannot be declined, since VEGF is a relevant neuroprotector and its targeting might give rise to possible negative side effects of RT. Available literature on this topic delineates a similar picture in animal models, where VEGF apart from stimulating microvascular proliferation and angiogenesis - enhances neuronal differentiation, protection, and regeneration $[39,136]$. Therefore, it is conceivable to assume that VEGF blockade augments irradiationinduced neurological toxicity $[137,138]$. Concerning neurocognitive performance, the RTOG 0825 consortium, in contrast to the AVAglio consortium, incorporated formal neurocognitive testing in order to assess cognitive performance. Intriguingly, adverse effects on processing speed and executive functions in patients receiving BEV as compared to patients in the standard arm were noted [34].

\section{CONCLUSIONS}

Overall, it remains unclear how the therapeutic alliance of RT and BEV application for GBM will develop. In our opinion, there are several open questions, which need to be addressed in the future.

Are there subgroups of patients who are specifically eligible or not suitable for BEV/RT treatment?

Having predictive biomarkers would be highly advisable, and a validation of already defined subgroups is of utmost importance.

What are the molecular mechanisms of BEV-

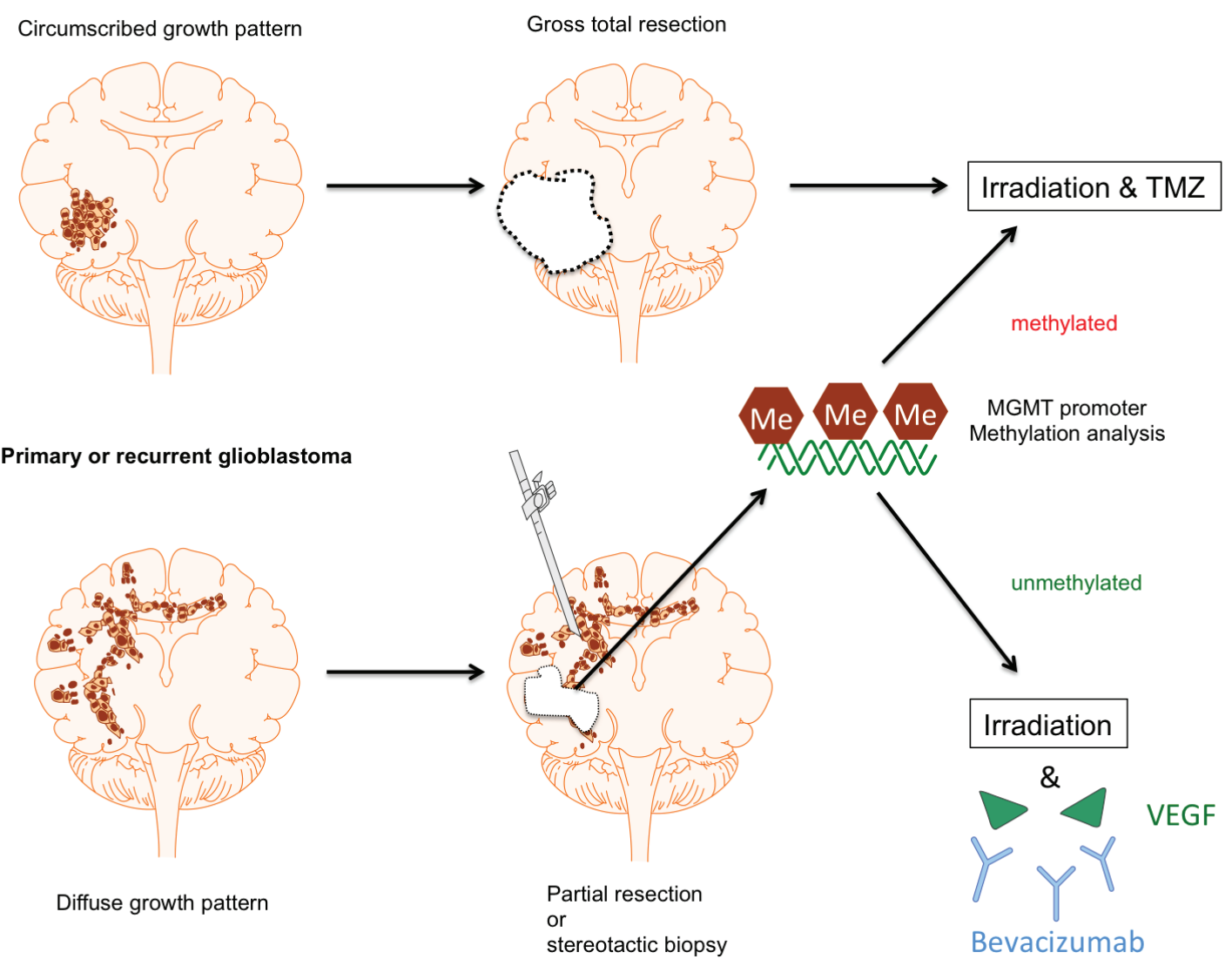

Figure 1: Proposal of patient stratification for BEV treatment in GBM. For GBM patients with gross total resection standard treatment including radiochemotherapy with TMZ is still considered to be the most promising therapy. The same applies for both completely and partially resected GBMs with MGMT promoter methylation, since this subcohort shows a significant benefit from TMZ chemotherapy. In contrast, patients with incompletely resected GBM in conjunction with a non-methylated MGMT promoter might considerably profit from (hypo)fractionated (re-)irradiation in combination with BEV treatment. 
mediated radioprotection of normal brain parenchyma and might dose-escalation make sense when detrimental effects on the normal tissue can be avoided?

It is relevant to delineate in how far dose escalation with concomitant BEV treatment is feasible.

After RT/BEV treatment, how long should maintenance BEV therapy be performed?

Some of the adverse effects could be related to sustained $\mathrm{BEV}$ treatment alone and not to the combined $\mathrm{RT} / \mathrm{BEV}$ regimen.

Clearly, future trials need to focus on patient subgroups for whom real benefits in terms of PFS and OS can be expected as depicted in Figure 1. Patients with both primary GBM or recurrent malignant glioma (pre-irradiated) should be considered. Out of these, patients with gross total resection should be excluded, since tortuous vessel formations, for which the combined effects of BEV and RT might be particularly helpful, are unlikely to be present. The same would apply to GBMs with methylated MGMT promoter, since RT plus TMZ alone is the treatment of choice in these cases, and there is little probability that BEV can add relevant improvement after two phase III trials without OS benefits. If a certain molecular subgroup, such as the mesenchymal GBM type, should be excluded continues to be unclear, and further studies addressing this question are needed. The remaining tumors will be the inoperable ones or the ones where only subtotal resection is possible due to the involvement of critical CNS structures. In these cases, dose escalation with concomitant BEV treatment might be considered and (hypo)fractionated re-irradiation might be a therapeutic option. The optimal duration of subsequent maintenance therapy with BEV remains yet to be determined, since it has not been proven that a perpetuation exerts relevant benefits and potential adverse side effects might be caused by long-term BEV treatment per se [139].

One facet of BEV treatment, which is currently moving into the focus of interest, and has not been intensively discussed here, are the immunological consequences of anti-angiogenic therapy. The tumor microenvironment and particularly the tumor endothelium appear to strongly impact on the regulation immune mechanisms and thus contribute to the establishment of an immunosuppressive milieu. VEGF has been attributed an essential role in this regard. Accordingly, interfering with VEGF function is known to have local as well as systemic immunological effects, which - not only due to the advent of immunotherapeutic approaches - certainly will be further examined in future studies [140, 141].

\section{ACKNOWLEDGMENTS}

This work was supported by the Friedrich-BaurStiftung. For Figure 1, a licensed version of the Motifolio drawing toolkits was used (www.motifolio.com).

\section{CONFLICTS OF INTERESTS}

MP is a scientific consultant for Roche $\mathrm{GmbH}$, Germany. The other authors declare that conflicts of interest do not exist.

\section{REFERENCES}

1. Plate KH, Scholz A, Dumont DJ. Tumor angiogenesis and anti-angiogenic therapy in malignant gliomas revisited. Acta Neuropathol 2012; 124: 763-775.

2. Das S, Marsden PA. Angiogenesis in glioblastoma. N Engl J Med 2013; 369: 1561-1563.

3. Wesseling P, Ruiter DJ, Burger PC. Angiogenesis in brain tumors; pathobiological and clinical aspects. J Neurooncol 1997; 32: 253-265.

4. Plate KH, Risau W. Angiogenesis in malignant gliomas. Glia 1995; 15: 339-347.

5. Jain RK, di Tomaso E, Duda DG, Loeffler JS, Sorensen AG, Batchelor TT. Angiogenesis in brain tumours. Nat Rev Neurosci 2007; 8: 610-622.

6. Carmeliet P, Jain RK. Molecular mechanisms and clinical applications of angiogenesis. Nature 2011; 473: 298-307.

7. Branco-Price C, Evans CE, Johnson RS. Endothelial hypoxic metabolism in carcinogenesis and dissemination: HIF-A isoforms are a NO metastatic phenomenon. Oncotarget 2013; 4: 2567-2576. doi: 10.18632/ oncotarget. 1461.

8. Chaudhry IH, O'Donovan DG, Brenchley PE, Reid H, Roberts IS. Vascular endothelial growth factor expression correlates with tumour grade and vascularity in gliomas. Histopathology 2001; 39: 409-415.

9. Plate KH, Breier G, Weich HA, Risau W. Vascular endothelial growth factor is a potential tumour angiogenesis factor in human gliomas in vivo. Nature 1992; 359: 845848.

10. Lund EL, Hog A, Olsen MW, Hansen LT, Engelholm SA, Kristjansen PE. Differential regulation of VEGF, HIF1alpha and angiopoietin-1, -2 and -4 by hypoxia and ionizing radiation in human glioblastoma. Int J Cancer 2004; 108: 833-838

11. McGee MC, Hamner JB, Williams RF, Rosati SF, Sims TL, Ng CY, Gaber MW, Calabrese C, Wu J, Nathwani AC, Duntsch C, Merchant TE, Davidoff AM. Improved intratumoral oxygenation through vascular normalization increases glioma sensitivity to ionizing radiation. Int $\mathrm{J}$ Radiat Oncol Biol Phys 2010; 76: 1537-1545.

12. Norden AD, Drappatz J, Wen PY. Novel anti-angiogenic therapies for malignant gliomas. Lancet Neurol 2008; 7 : 1152-1160.

13. Jenab-Wolcott J, Giantonio BJ. Bevacizumab: current indications and future development for management of solid tumors. Expert Opinion on Biological Therapy 2009; 9: 507-517. 
14. Gutin PH, Iwamoto FM, Beal K, Mohile NA, Karimi S, Hou BL, Lymberis S, Yamada Y, Chang J, Abrey LE. Safety and efficacy of bevacizumab with hypofractionated stereotactic irradiation for recurrent malignant gliomas. Int J Radiat Oncol Biol Phys 2009; 75: 156-163.

15. Lai A, Filka E, McGibbon B, Nghiemphu PL, Graham C, Yong WH, Mischel P, Liau LM, Bergsneider M, Pope W, Selch M, Cloughesy T. Phase II pilot study of bevacizumab in combination with temozolomide and regional radiation therapy for up-front treatment of patients with newly diagnosed glioblastoma multiforme: interim analysis of safety and tolerability. Int J Radiat Oncol Biol Phys 2008; 71: 1372-1380.

16. Narayana A, Golfinos JG, Fischer I, Raza S, Kelly P, Parker E, Knopp EA, Medabalmi P, Zagzag D, Eagan P, Gruber ML. Feasibility of using bevacizumab with radiation therapy and temozolomide in newly diagnosed high-grade glioma. Int J Radiat Oncol Biol Phys 2008; 72: 383-389.

17. Kil WJ, Tofilon PJ, Camphausen K. Post-radiation increase in VEGF enhances glioma cell motility in vitro. Radiat Oncol 2012; 7: 25.

18. Jiang X, Engelbach JA, Yuan L, Cates J, Gao F, Drzymala RE, Hallahan DE, Rich KM, Schmidt RE, Ackerman JJ, Garbow JR. Anti-VEGF antibodies mitigate the development of radiation necrosis in mouse brain. Clin Cancer Res 2014; 20: 2695-2702.

19. Bokstein F, Shpigel S, Blumenthal DT. Treatment with bevacizumab and irinotecan for recurrent high-grade glial tumors. Cancer 2008; 112: 2267-2273.

20. Chamberlain MC. Bevacizumab plus irinotecan in recurrent glioblastoma. J Clin Oncol 2008; 26: 1012-1013; author reply 1013.

21. Desjardins A, Reardon DA, Herndon JE, 2nd, Marcello J, Quinn JA, Rich JN, Sathornsumetee S, Gururangan S, Sampson J, Bailey L, Bigner DD, Friedman AH, Friedman HS, Vredenburgh JJ. Bevacizumab plus irinotecan in recurrent WHO grade 3 malignant gliomas. Clin Cancer Res 2008; 14: 7068-7073.

22. de Groot JF, Yung WK. Bevacizumab and irinotecan in the treatment of recurrent malignant gliomas. Cancer J 2008; 14: 279-285.

23. Kreisl TN, Kim L, Moore K, Duic P, Royce C, Stroud I, Garren N, Mackey M, Butman JA, Camphausen K, Park J, Albert PS, Fine HA. Phase II Trial of Single-Agent Bevacizumab Followed by Bevacizumab Plus Irinotecan at Tumor Progression in Recurrent Glioblastoma. Journal of Clinical Oncology 2009; 27: 740-745.

24. Poulsen HS, Grunnet K, Sorensen M, Olsen P, Hasselbalch B, Nelausen K, Kosteljanetz M, Lassen U. Bevacizumab plus irinotecan in the treatment patients with progressive recurrent malignant brain tumours. Acta Oncol 2009; 48: 52-58.

25. Vredenburgh JJ, Desjardins A, Herndon JE, 2nd, Marcello J, Reardon DA, Quinn JA, Rich JN, Sathornsumetee S,
Gururangan S, Sampson J, Wagner M, Bailey L, Bigner DD, Friedman AH, Friedman HS. Bevacizumab plus irinotecan in recurrent glioblastoma multiforme. J Clin Oncol 2007; 25: 4722-4729.

26. Desjardins A, Vredenburgh JJ, Gururangan S, Peters KB, Friedman AH, Friedman H, Reardon DA. A phase II study of bevacizumab plus etoposide among recurrent malignant glioma patients. Neuro-Oncology 2009; 11: 633-633.

27. Reardon D, Desjardins A, Vredenburgh JJ, Gururangan S, Peters KB, Norfleet JA: Bevacizumab plus etoposide among recurrent malignant glioma patients: Phase II study final results. In ASCO Annual Meeting. 2009

28. Soffietti R, Rudà R, Trevisan E, Picco E, Guarneri D, Caroli M, Fabrini M, Scotti V: Phase II study of bevacizumab and nitrosourea in patients with recurrent malignant glioma: A multicenter Italian study. In ASCO Annual Meeting. 2009

29. Sathornsumetee S, Desjardins A, Vredenburgh JJ, Rich JN, Gururangan S, Friedman AH, Friedman HS, Reardon DA: Phase II study of bevacizumab plus erlotinib for recurrent malignant gliomas. In ASCO Annual Meeting. 2009

30. Thompson EM, Dosa E, Kraemer DF, Neuwelt EA. Bevacizumab plus carboplatin increases survival in patients with recurrent malignant glioma. Neuro-Oncology 2009; 11: $625-626$.

31. Gallego Perez-Larraya J, Lahutte M, Petrirena G, ReyesBotero G, Gonzalez-Aguilar A, Houillier C, Guillevin R, Sanson M, Hoang-Xuan K, Delattre JY. Response assessment in recurrent glioblastoma treated with irinotecan-bevacizumab: comparative analysis of the Macdonald, RECIST, RANO, and RECIST + F criteria. Neuro Oncol 2012; 14: 667-673.

32. Chinot OL, Macdonald DR, Abrey LE, Zahlmann G, Kerloeguen Y, Cloughesy TF. Response assessment criteria for glioblastoma: practical adaptation and implementation in clinical trials of antiangiogenic therapy. Curr Neurol Neurosci Rep 2013; 13: 347.

33. Chinot OL, Wick W, Mason W, Henriksson R, Saran F, Nishikawa R, Carpentier AF, Hoang-Xuan K, Kavan P, Cernea D, Brandes AA, Hilton M, Abrey L, Cloughesy T. Bevacizumab plus radiotherapy-temozolomide for newly diagnosed glioblastoma. N Engl J Med 2014; 370: 709-722.

34. Gilbert MR, Dignam JJ, Armstrong TS, Wefel JS, Blumenthal DT, Vogelbaum MA, Colman H, Chakravarti A, Pugh S, Won M, Jeraj R, Brown PD, Jaeckle KA, Schiff D, Stieber VW, Brachman DG, Werner-Wasik M, TremontLukats IW, et al. A randomized trial of bevacizumab for newly diagnosed glioblastoma. N Engl J Med 2014; 370: 699-708.

35. Norden AD, Young GS, Setayesh K, Muzikansky A, Klufas R, Ross GL, Ciampa AS, Ebbeling LG, Levy B, Drappatz J, Kesari S, Wen PY. Bevacizumab for recurrent malignant gliomas: efficacy, toxicity, and patterns of recurrence. Neurology 2008; 70: 779-787.

36. Pope WB, Lai A, Mehta R, Kim HJ, Qiao J, Young JR, 
Xue X, Goldin J, Brown MS, Nghiemphu PL, Tran A, Cloughesy TF. Apparent diffusion coefficient histogram analysis stratifies progression-free survival in newly diagnosed bevacizumab-treated glioblastoma. AJNR Am J Neuroradiol 2011; 32: 882-889.

37. Lamszus K, Kunkel P, Westphal M. Invasion as limitation to anti-angiogenic glioma therapy. Acta Neurochir Suppl 2003; 88: 169-177.

38. Wick W, Chinot OL, Mason WP, Henriksson R, Saran F, Nishikawa R, Revil C, Kerloeguen Y, Cloughesy TF. Patterns of tumor progression in a phase 3 study of bevacizumab (Bv) plus radiotherapy (RT) plus temozolomide (T) for newly diagnosed glioblastoma (GB). J Clin Oncol 2014; 32:5s, (suppl; abstr 2051^).

39. Jin K, Zhu Y, Sun Y, Mao XO, Xie L, Greenberg DA. Vascular endothelial growth factor (VEGF) stimulates neurogenesis in vitro and in vivo. Proc Natl Acad Sci U S A 2002; 99: 11946-11950.

40. Guo J, Shinriki S, Su Y, Nakamura T, Hayashi M, Tsuda Y, Murakami Y, Tasaki M, Hide T, Takezaki T, Kuratsu J, Yamashita S, Ueda M, Li JD, Ando Y, Jono H. Hypoxia suppresses cylindromatosis (CYLD) expression to promote inflammation in glioblastoma: possible link to acquired resistance to anti-VEGF therapy. Oncotarget 2014; 5: 6353 6364. doi: 10.18632/oncotarget.2216.

41. Batchelor TT, Reardon DA, de Groot JF, Wick W, Weller M. Antiangiogenic therapy for glioblastoma: current status and future prospects. Clin Cancer Res 2014; 20: 5612-5619.

42. Jain RK. Normalization of tumor vasculature: an emerging concept in antiangiogenic therapy. Science 2005; 307: 5862.

43. Winkler F, Kozin SV, Tong RT, Chae SS, Booth MF, Garkavtsev I, Xu L, Hicklin DJ, Fukumura D, di Tomaso E, Munn LL, Jain RK. Kinetics of vascular normalization by VEGFR2 blockade governs brain tumor response to radiation: role of oxygenation, angiopoietin-1, and matrix metalloproteinases. Cancer Cell 2004; 6: 553-563.

44. Dings RP, Loren M, Heun H, McNiel E, Griffioen AW, Mayo KH, Griffin RJ. Scheduling of radiation with angiogenesis inhibitors anginex and Avastin improves therapeutic outcome via vessel normalization. Clin Cancer Res 2007; 13: 3395-3402.

45. Mondini M, Nizard M, Tran T, Mauge L, Loi M, Clemenson C, Dugue D, Maroun P, Louvet E, Adam J, Badoual C, Helley D, Dransart E, Johannes L, Vozenin MC, Perfettini JL, Tartour E, Deutsch E. Synergy of Radiotherapy and a Cancer Vaccine for the Treatment of HPV-Associated Head and Neck Cancer. Molecular cancer therapeutics 2015; 14: 1336-1345.

46. Potiron VA, Abderrahmani R, Clement-Colmou K, Marionneau-Lambot S, Oullier T, Paris F, Supiot $\mathrm{S}$. Improved functionality of the vasculature during conventionally fractionated radiation therapy of prostate cancer. PloS one 2013; 8: e84076.
47. Batchelor TT, Gerstner ER, Emblem KE, Duda DG, Kalpathy-Cramer J, Snuderl M, Ancukiewicz M, Polaskova P, Pinho MC, Jennings D, Plotkin SR, Chi AS, Eichler AF, Dietrich J, Hochberg FH, Lu-Emerson C, Iafrate AJ, Ivy $\mathrm{SP}$, et al. Improved tumor oxygenation and survival in glioblastoma patients who show increased blood perfusion after cediranib and chemoradiation. Proc Natl Acad Sci U S A 2013; 110: 19059-19064.

48. von Baumgarten L, Brucker D, Tirniceru A, Kienast Y, Grau S, Burgold S, Herms J, Winkler F. Bevacizumab has differential and dose-dependent effects on glioma blood vessels and tumor cells. Clin Cancer Res 2011; 17: 61926205.

49. Kessler T, Sahm F, Blaes J, Osswald M, Rubmann P, Milford D, Urban S, Jestaedt L, Heiland S, Bendszus M, Hertenstein A, Pfenning PN, Ruiz de Almodovar $\mathrm{C}$, et al.. Glioma cell VEGFR-2 confers resistance to chemotherapeutic and antiangiogenic treatments in PTENdeficient glioblastoma. Oncotarget 2015; 6:31050-68. doi: 10.18632/oncotarget.2910.

50. Baker GJ, Yadav VN, Motsch S, Koschmann C, Calinescu AA, Mineharu Y, Camelo-Piragua SI, Orringer D, Bannykh S, Nichols WS, deCarvalho AC, Mikkelsen T, Castro MG, Lowenstein PR. Mechanisms of glioma formation: iterative perivascular glioma growth and invasion leads to tumor progression, VEGF-independent vascularization, and resistance to antiangiogenic therapy. Neoplasia 2014; 16 : 543-561.

51. Hamerlik P, Lathia JD, Rasmussen R, Wu Q, Bartkova J, Lee M, Moudry P, Bartek J, Jr., Fischer W, Lukas J, Rich JN, Bartek J. Autocrine VEGF-VEGFR2-Neuropilin-1 signaling promotes glioma stem-like cell viability and tumor growth. J Exp Med 2012; 209: 507-520.

52. Schittenhelm J, Simon P, Harter PN, Zachskorn C, Schlaszus H, Rottger F, Winkels M, Weller M, Meyermann R, Mittelbronn M. CD133 expression is associated with small round blue cell tumour morphology in human central nervous system neoplasms. Histopathology 2011; 58: 739749.

53. Gabrusiewicz K, Liu D, Cortes-Santiago N, Hossain MB, Conrad CA, Aldape KD, Fuller GN, Marini FC, Alonso MM, Idoate MA, Gilbert MR, Fueyo J, Gomez-Manzano C. Anti-vascular endothelial growth factor therapy-induced glioma invasion is associated with accumulation of Tie2expressing monocytes. Oncotarget 2014; 5: 2208-2220. doi: 10.18632/oncotarget.1893.

54. Keunen O, Johansson M, Oudin A, Sanzey M, Rahim SA, Fack F, Thorsen F, Taxt T, Bartos M, Jirik R, Miletic H, Wang J, Stieber D, et al.. Anti-VEGF treatment reduces blood supply and increases tumor cell invasion in glioblastoma. Proc Natl Acad Sci U S A 2011; 108: 37493754.

55. Mesti T, Savarin P, Triba MN, Le Moyec L, Ocvirk J, Banissi C, Carpentier AF. Metabolic impact of antiangiogenic agents on U87 glioma cells. PloS one 2014; 9: 
e99198.

56. Fack F, Espedal H, Keunen O, Golebiewska A, Obad N, Harter PN, Mittelbronn M, Bahr O, Weyerbrock A, Stuhr L, Miletic H, Sakariassen PO, Stieber D, et al.. Bevacizumab treatment induces metabolic adaptation toward anaerobic metabolism in glioblastomas. Acta Neuropathol 2015; 129: 115-131.

57. Hattingen E, Jurcoane A, Bahr O, Rieger J, Magerkurth J, Anti S, Steinbach JP, Pilatus U. Bevacizumab impairs oxidative energy metabolism and shows antitumoral effects in recurrent glioblastomas: a 31P/1H MRSI and quantitative magnetic resonance imaging study. Neuro Oncol 2011; 13: 1349-1363.

58. Hattingen E, Bahr O, Rieger J, Blasel S, Steinbach J, Pilatus U. Phospholipid metabolites in recurrent glioblastoma: in vivo markers detect different tumor phenotypes before and under antiangiogenic therapy. PloS one 2013; 8: e56439.

59. Ali SA, McHayleh WM, Ahmad A, Sehgal R, Braffet M, Rahman M, Bejjani G, Friedland DM. Bevacizumab and irinotecan therapy in glioblastoma multiforme: a series of 13 cases. J Neurosurg 2008; 109: 268-272.

60. Sathornsumetee S, Cao Y, Marcello JE, Herndon JE, 2nd, McLendon RE, Desjardins A, Friedman HS, Dewhirst MW, Vredenburgh JJ, Rich JN. Tumor angiogenic and hypoxic profiles predict radiographic response and survival in malignant astrocytoma patients treated with bevacizumab and irinotecan. J Clin Oncol 2008; 26: 271-278.

61. Ananthnarayan S, Bahng J, Roring J, Nghiemphu P, Lai A, Cloughesy T, Pope WB. Time course of imaging changes of GBM during extended bevacizumab treatment. J Neurooncol 2008; 88: 339-347.

62. Hattingen E, Jurcoane A, Daneshvar K, Pilatus U, Mittelbronn M, Steinbach JP, Bahr O. Quantitative T2 mapping of recurrent glioblastoma under bevacizumab improves monitoring for non-enhancing tumor progression and predicts overall survival. Neuro Oncol 2013; 15: 13951404.

63. Ellingson BM, Kim HJ, Woodworth DC, Pope WB, Cloughesy JN, Harris RJ, Lai A, Nghiemphu PL, Cloughesy TF. Recurrent glioblastoma treated with bevacizumab: contrast-enhanced T1-weighted subtraction maps improve tumor delineation and aid prediction of survival in a multicenter clinical trial. Radiology 2014; 271: 200-210.

64. Lescher S, Jurcoane A, Veit A, Bahr O, Deichmann R, Hattingen E. Quantitative T1 and T2 mapping in recurrent glioblastomas under bevacizumab: earlier detection of tumor progression compared to conventional MRI. Neuroradiology 2015; 57: 11-20.

65. Sawlani RN, Raizer J, Horowitz SW, Shin W, Grimm SA, Chandler JP, Levy R, Getch C, Carroll TJ. Glioblastoma: a method for predicting response to antiangiogenic chemotherapy by using MR perfusion imaging-pilot study. Radiology 2010; 255: 622-628.

66. Bahr O, Hattingen E, Rieger J, Steinbach JP. Bevacizumab- induced tumor calcifications as a surrogate marker of outcome in patients with glioblastoma. Neuro Oncol 2011; 13: 1020-1029.

67. Bahr O, Harter PN, Weise LM, You SJ, Mittelbronn M, Ronellenfitsch MW, Rieger J, Steinbach JP, Hattingen E. Sustained focal antitumor activity of bevacizumab in recurrent glioblastoma. Neurology 2014; 83: 227-234.

68. Nowosielski M, Wiestler B, Goebel G, Hutterer M, Schlemmer HP, Stockhammer G, Wick W, Bendszus M, Radbruch A. Progression types after antiangiogenic therapy are related to outcome in recurrent glioblastoma. Neurology 2014; 82: 1684-1692.

69. Hygino da Cruz LC, Jr., Rodriguez I, Domingues RC, Gasparetto EL, Sorensen AG. Pseudoprogression and pseudoresponse: imaging challenges in the assessment of posttreatment glioma. AJNR Am J Neuroradiol 2011; 32: 1978-1985.

70. Hutterer M, Nowosielski M, Putzer D, Waitz D, Tinkhauser G, Kostron H, Muigg A, Virgolini IJ, Staffen W, Trinka E, Gotwald T, Jacobs AH, Stockhammer G. O-(2-18F-fluoroethyl)-L-tyrosine PET predicts failure of antiangiogenic treatment in patients with recurrent highgrade glioma. J Nucl Med 2011; 52: 856-864.

71. Galldiks N, Rapp M, Stoffels G, Fink GR, Shah NJ, Coenen HH, Sabel M, Langen KJ. Response assessment of bevacizumab in patients with recurrent malignant glioma using [18F]Fluoroethyl-L-tyrosine PET in comparison to MRI. Eur J Nucl Med Mol Imaging 2013; 40: 22-33.

72. Niyazi M, Jansen N, Ganswindt U, Schwarz SB, Geisler J, Schnell O, Busing K, Eigenbrod S, la Fougere C, Belka C. Re-irradiation in recurrent malignant glioma: prognostic value of [18F]FET-PET. J Neurooncol 2012; 110: 389-395.

73. Beal K, Abrey LE, Gutin PH. Antiangiogenic agents in the treatment of recurrent or newly diagnosed glioblastoma: analysis of single-agent and combined modality approaches. Radiat Oncol 2011; 6: 2.

74. Stupp R, Mason WP, van den Bent MJ, Weller M, Fisher B, Taphoorn MJ, Belanger K, Brandes AA, Marosi C, Bogdahn U, Curschmann J, Janzer RC, Ludwin SK, Gorlia T, Allgeier A, Lacombe D, Cairncross JG, Eisenhauer E, Mirimanoff RO. Radiotherapy plus concomitant and adjuvant temozolomide for glioblastoma. N Engl J Med 2005; 352: 987-996.

75. Stupp R, Hegi ME, Mason WP, van den Bent MJ, Taphoorn MJ, Janzer RC, Ludwin SK, Allgeier A, Fisher B, Belanger K, Hau P, Brandes AA, Gijtenbeek J, Marosi C, Vecht CJ, Mokhtari K, Wesseling P, Villa S, et al. Effects of radiotherapy with concomitant and adjuvant temozolomide versus radiotherapy alone on survival in glioblastoma in a randomised phase III study: 5-year analysis of the EORTCNCIC trial. Lancet Oncol 2009; 10: 459-466.

76. Herrlinger U, Schaefer N, Steinbach JP, Weyerbrock A, Hau P, Goldbrunner R, Friedrich F, Rohde V, Ringel F, Braun C, Kohnen R, Leutgeb B, Belka C, Urbach H, Stummer W, Glas M. Survival and quality of life in the 
randomized, multicenter GLARIUS trial investigating bevacizumab/irinotecan versus standard temozolomide in newly diagnosed, MGMT-non-methylated glioblastoma patients. J Clin Oncol 2014; 32:5s, 2014 (suppl; abstr 2042)

77. Taal W, Oosterkamp HM, Walenkamp AM, Dubbink HJ, Beerepoot LV, Hanse MC, Buter J, Honkoop AH, Boerman D, de Vos FY, Dinjens WN, Enting RH, Taphoorn MJ, van den Berkmortel FW, Jansen RL, Brandsma D, Bromberg JE, van Heuvel I, et al. Single-agent bevacizumab or lomustine versus a combination of bevacizumab plus lomustine in patients with recurrent glioblastoma (BELOB trial): a randomised controlled phase 2 trial. Lancet Oncol 2014; 15: 943-953.

78. Tong RT, Boucher Y, Kozin SV, Winkler F, Hicklin DJ, Jain RK. Vascular normalization by vascular endothelial growth factor receptor 2 blockade induces a pressure gradient across the vasculature and improves drug penetration in tumors. Cancer research 2004; 64: 37313736 .

79. Trog D, Yeghiazaryan K, Fountoulakis M, Friedlein A, Moenkemann H, Haertel N, Schueller H, Breipohl W, Schild H, Leppert D, Golubnitschaja O. Pro-invasive gene regulating effect of irradiation and combined temozolomide-radiation treatment on surviving human malignant glioma cells. Eur J Pharmacol 2006; 542: 8-15.

80. Wild-Bode C, Weller M, Wick W. Molecular determinants of glioma cell migration and invasion. J Neurosurg 2001; 94: 978-984.

81. Pei J, Park IH, Ryu HH, Li SY, Li CH, Lim SH, Wen M, Jang WY, Jung S. Sublethal dose of irradiation enhances invasion of malignant glioma cells through p53-MMP 2 pathway in U87MG mouse brain tumor model. Radiat Oncol 2015; 10: 164.

82. Kioi M, Vogel H, Schultz G, Hoffman RM, Harsh GR, Brown JM. Inhibition of vasculogenesis, but not angiogenesis, prevents the recurrence of glioblastoma after irradiation in mice. J Clin Invest 2010; 120: 694-705.

83. Duda DG, Ancukiewicz M, Jain RK. Biomarkers of antiangiogenic therapy: how do we move from candidate biomarkers to valid biomarkers? J Clin Oncol 2010; 28: 183-185.

84. Hayashi H, Arao T, Matsumoto K, Kimura H, Togashi Y, Hirashima Y, Horita Y, Iwasa S, Okita NT, Honma Y, Takashima A, Kato K, Hamaguchi T, et al.. Biomarkers of reactive resistance and early disease progression during chemotherapy plus bevacizumab treatment for colorectal carcinoma. Oncotarget 2014; 5: 2588-2595. doi: 10.18632/ oncotarget.1811.

85. Jubb AM, Harris AL. Biomarkers to predict the clinical efficacy of bevacizumab in cancer. Lancet Oncol 2010; 11: 1172-1183.

86. Hegde PS, Jubb AM, Chen D, Li NF, Meng YG, Bernaards C, Elliott R, Scherer SJ, Chen DS. Predictive impact of circulating vascular endothelial growth factor in four phase
III trials evaluating bevacizumab. Clin Cancer Res 2013; 19: 929-937.

87. Nishikawa R, Saran F, Mason W, Wick W, Cloughesy TF, Henriksson R, Hilton M, Garcia J, Vogt T, Pallaud $\mathrm{C}$, Chinot OL. Biomarker (BM) evaluations in the phase III AVAglio study of bevacizumab (Bv) plus standard radiotherapy (RT) and temozolomide (T) for newly diagnosed glioblastoma (GBM). J Clin Oncol 2013; 31, (suppl; abstr 2023^).

88. Cuppini L, Calleri A, Bruzzone MG, Prodi E, Anghileri E, Pellegatta S, Mancuso P, Porrati P, Di Stefano AL, Ceroni M, Bertolini F, Finocchiaro G, Eoli M. Prognostic value of CD109+ circulating endothelial cells in recurrent glioblastomas treated with bevacizumab and irinotecan. PloS one 2013; 8: e74345.

89. Tabouret E, Boudouresque F, Barrie M, Matta M, Boucard C, Loundou A, Carpentier A, Sanson M, Metellus P, Figarella-Branger D, Ouafik L, Chinot O. Association of matrix metalloproteinase 2 plasma level with response and survival in patients treated with bevacizumab for recurrent high-grade glioma. Neuro Oncol 2014; 16: 392-399.

90. Verhaak RG, Hoadley KA, Purdom E, Wang V, Qi Y, Wilkerson MD, Miller CR, Ding L, Golub T, Mesirov JP, Alexe G, Lawrence M, O`Kelly M, Tamayo P, Weir BA, Gabriel S, Winckler W, Gupta S, et al. Integrated genomic analysis identifies clinically relevant subtypes of glioblastoma characterized by abnormalities in PDGFRA, IDH1, EGFR, and NF1. Cancer Cell 2010; 17: 98-110.

91. Phillips HS, Kharbanda S, Chen R, Forrest WF, Soriano RH, Wu TD, Misra A, Nigro JM, Colman H, Soroceanu L, Williams PM, Modrusan Z, Feuerstein BG, Aldape K. Molecular subclasses of high-grade glioma predict prognosis, delineate a pattern of disease progression, and resemble stages in neurogenesis. Cancer Cell 2006; 9: 157173.

92. Colman H, Zhang L, Sulman EP, McDonald JM, Shooshtari NL, Rivera A, Popoff S, Nutt CL, Louis DN, Cairncross JG, Gilbert MR, Phillips HS, Mehta MP, et al.. A multigene predictor of outcome in glioblastoma. Neuro Oncol 2010; 12: 49-57.

93. Sulman EP, Won M, Blumenthal DT, Vogelbaum MA, Colman H, Jenkins RB, Chakravarti A, Jeraj R, Brown PD, Jaeckle KA, Schiff D, Dignam J, Atkins JN, Brachman D, Werner-Wasik M, Komaki R, Gilbert MR, Mehta MP, Aldape KD. Molecular predictors of outcome and response to bevacizumab (BEV) based on analysis of RTOG 0825, a phase III trial comparing chemoradiation (CRT) with and without $\mathrm{BEV}$ in patients with newly diagnosed glioblastoma (GBM). J Clin Oncol 2013; 31, (suppl; abstr LBA2010).

94. Phillips H, Sandmann T, Li C, Cloughesy T, Chinot O, Wick W, Nishikawa R, Mason WP, Henriksson R, Saran F, Lai A, Moore N, Hegde PS, Abrey LE, Bourgon R, Garcia J, Bais C. Correlation of molecular subtypes with survival in AVAglio (bevacizumab [Bv] and radiotherapy [RT] and temozolomide [T] for newly diagnosed glioblastoma [GB]). 
J Clin Oncol 2014; 32:5s, (suppl; abstr 2001^).

95. Gorski DH, Beckett MA, Jaskowiak NT, Calvin DP, Mauceri HJ, Salloum RM, Seetharam S, Koons A, Hari DM, Kufe DW, Weichselbaum RR. Blockage of the vascular endothelial growth factor stress response increases the antitumor effects of ionizing radiation. Cancer research 1999; 59: 3374-3378.

96. Geng L, Donnelly E, McMahon G, Lin PC, Sierra-Rivera E, Oshinka H, Hallahan DE. Inhibition of vascular endothelial growth factor receptor signaling leads to reversal of tumor resistance to radiotherapy. Cancer research 2001; 61: 24132419.

97. Gupta AK, Mann SB, Khosla VK, Sastry KV, Hundal JS. Non-randomized comparison of surgical modalities for paranasal sinus mycoses with intracranial extension. Mycoses 1999; 42: 225-230.

98. Hovinga KE, Stalpers LJ, van Bree C, Donker M, Verhoeff JJ, Rodermond HM, Bosch DA, van Furth WR. Radiationenhanced vascular endothelial growth factor (VEGF) secretion in glioblastoma multiforme cell lines - a clue to radioresistance? J Neurooncol 2005; 74: 99-103.

99. Verhoeff JJ, Stalpers LJ, Claes A, Hovinga KE, Musters GD, Peter Vandertop W, Richel DJ, Leenders WP, van Furth WR. Tumour control by whole brain irradiation of anti-VEGF-treated mice bearing intracerebral glioma. Eur J Cancer 2009; 45: 3074-3080.

100. Wachsberger PR, Burd R, Cardi C, Thakur M, Daskalakis C, Holash J, Yancopoulos GD, Dicker AP. VEGF trap in combination with radiotherapy improves tumor control in u87 glioblastoma. Int J Radiat Oncol Biol Phys 2007; 67: 1526-1537.

101. Hoang T, Huang S, Armstrong E, Eickhoff JC, Harari PM. Enhancement of radiation response with bevacizumab. J Exp Clin Cancer Res 2012; 31: 37.

102. Levin VA, Bidaut L, Hou P, Kumar AJ, Wefel JS, Bekele BN, Grewal J, Prabhu S, Loghin M, Gilbert MR, Jackson EF. Randomized double-blind placebo-controlled trial of bevacizumab therapy for radiation necrosis of the central nervous system. Int J Radiat Oncol Biol Phys 2011; 79: 1487-1495.

103. Badiyan SN, Markovina S, Simpson JR, Robinson CG, DeWees T, Tran DD, Linette G, Jalalizadeh R, Dacey R, Rich KM, Chicoine MR, Dowling JL, Leuthardt EC, Zipfel GJ, Kim AH, Huang J. Radiation therapy dose escalation for glioblastoma multiforme in the era of temozolomide. Int J Radiat Oncol Biol Phys 2014; 90: 877-885.

104. McPherson CM, Gerena-Lewis M, Breneman JC, Warnick RE. Results of phase I study of a multi-modality treatment for newly diagnosed glioblastoma multiforme using local implantation of concurrent BCNU wafers and permanent I-125 seeds followed by fractionated radiation and temozolomide chemotherapy. J Neurooncol 2012; 108: 521525.

105. Burnet NG, Jena R, Jefferies SJ, Stenning SP, Kirkby
NF. Mathematical modelling of survival of glioblastoma patients suggests a role for radiotherapy dose escalation and predicts poorer outcome after delay to start treatment. Clin Oncol (R Coll Radiol) 2006; 18: 93-103.

106. Fitzek MM, Thornton AF, Rabinov JD, Lev MH, Pardo FS, Munzenrider JE, Okunieff P, Bussiere M, Braun I, Hochberg FH, Hedley-Whyte ET, Liebsch NJ, Harsh GRt. Accelerated fractionated proton/photon irradiation to 90 cobalt gray equivalent for glioblastoma multiforme: results of a phase II prospective trial. J Neurosurg 1999; 91: 251260.

107. Souhami L, Seiferheld W, Brachman D, Podgorsak EB, Werner-Wasik M, Lustig R, Schultz CJ, Sause W, Okunieff P, Buckner J, Zamorano L, Mehta MP, Curran WJ, Jr. Randomized comparison of stereotactic radiosurgery followed by conventional radiotherapy with carmustine to conventional radiotherapy with carmustine for patients with glioblastoma multiforme: report of Radiation Therapy Oncology Group 93-05 protocol. Int J Radiat Oncol Biol Phys 2004; 60: 853-860.

108. Niyazi M, Schnell O, Suchorska B, Schwarz SB, Ganswindt U, Geisler J, Bartenstein P, Kreth FW, Tonn JC, Eigenbrod $\mathrm{S}$, Belka C, la Fougere C. FET-PET assessed recurrence pattern after radio-chemotherapy in newly diagnosed patients with glioblastoma is influenced by MGMT methylation status. Radiother Oncol 2012; 104: 78-82.

109. Gebhardt BJ, Dobelbower MC, Ennis WH, Bag AK, Markert JM, Fiveash JB. Patterns of failure for glioblastoma multiforme following limited-margin radiation and concurrent temozolomide. Radiat Oncol 2014; 9: 130.

110. Ogura K, Mizowaki T, Arakawa Y, Ogura M, Sakanaka K, Miyamoto S, Hiraoka M. Initial and cumulative recurrence patterns of glioblastoma after temozolomide-based chemoradiotherapy and salvage treatment: a retrospective cohort study in a single institution. Radiat Oncol 2013; 8: 97.

111. Tsien C, Moughan J, Michalski JM, Gilbert MR, Purdy J, Simpson J, Kresel JJ, Curran WJ, Diaz A, Mehta MP. Phase I three-dimensional conformal radiation dose escalation study in newly diagnosed glioblastoma: Radiation Therapy Oncology Group Trial 98-03. Int J Radiat Oncol Biol Phys 2009; 73: 699-708.

112. Miyata T, Toho T, Nonoguchi N, Furuse M, Kuwabara H, Yoritsune E, Kawabata S, Kuroiwa T, Miyatake S. The roles of platelet-derived growth factors and their receptors in brain radiation necrosis. Radiat Oncol 2014; 9: 51.

113. Matuschek C, Bolke E, Nawatny J, Hoffmann TK, Peiper M, Orth K, Gerber PA, Rusnak E, Lammering G, Budach $\mathrm{W}$. Bevacizumab as a treatment option for radiation-induced cerebral necrosis. Strahlenther Onkol 2011; 187: 135-139.

114. Furuse M, Kawabata S, Kuroiwa T, Miyatake S. Repeated treatments with bevacizumab for recurrent radiation necrosis in patients with malignant brain tumors: a report of 2 cases. J Neurooncol 2011; 102: 471-475.

115. Niyazi M, Flieger M, Ganswindt U, Combs SE, Belka C. 
Validation of the prognostic Heidelberg re-irradiation score in an independent mono-institutional patient cohort. Radiat Oncol 2014; 9: 128.

116. Niyazi M, Siefert A, Schwarz SB, Ganswindt U, Kreth FW, Tonn JC, Belka C. Therapeutic options for recurrent malignant glioma. Radiother Oncol 2011; 98: 1-14.

117. Ciammella P, Podgornii A, Galeandro M, D'Abbiero $\mathrm{N}$, Pisanello A, Botti A, Cagni E, Iori M, Iotti C. Hypofractionated stereotactic radiation therapy for recurrent glioblastoma: single institutional experience. Radiat Oncol 2013; 8: 222.

118. Scholtyssek F, Zwiener I, Schlamann A, Seidel C, Meixensberger J, Bauer M, Hoffmann KT, Combs SE, von Bueren AO, Kortmann RD, Muller K. Reirradiation in progressive high-grade gliomas: outcome, role of concurrent chemotherapy, prognostic factors and validation of a new prognostic score with an independent patient cohort. Radiat Oncol 2013; 8: 161.

119. Miwa K, Matsuo M, Ogawa S, Shinoda J, Yokoyama K, Yamada J, Yano H, Iwama T. Re-irradiation of recurrent glioblastoma multiforme using 11C-methionine PET/ CT/MRI image fusion for hypofractionated stereotactic radiotherapy by intensity modulated radiation therapy. Radiat Oncol 2014; 9: 181.

120. Muller K, Scheithauer H, Pietschmann S, Hoffmann M, Rossler J, Graf N, Baumert BG, Christiansen H, Kortmann $\mathrm{RD}$, Kramm CM, von Bueren AO. Reirradiation as part of a salvage treatment approach for progressive non-pontine pediatric high-grade gliomas: preliminary experiences from the German HIT-HGG study group. Radiat Oncol 2014; 9: 177.

121. Niyazi M, Karin I, Sohn M, Nachbichler SB, Lang P, Belka C, Ganswindt U. Analysis of equivalent uniform dose (EUD) and conventional radiation treatment parameters after primary and re-irradiation of malignant glioma. Radiat Oncol 2013; 8: 287.

122. Cuneo KC, Vredenburgh JJ, Sampson JH, Reardon DA, Desjardins A, Peters KB, Friedman HS, Willett CG, Kirkpatrick JP. Safety and efficacy of stereotactic radiosurgery and adjuvant bevacizumab in patients with recurrent malignant gliomas. Int J Radiat Oncol Biol Phys 2012; 82: 2018-2024.

123. Niyazi M, Ganswindt U, Schwarz SB, Kreth FW, Tonn JC, Geisler J, la Fougere C, Ertl L, Linn J, Siefert A, Belka C. Irradiation and bevacizumab in high-grade glioma retreatment settings. Int J Radiat Oncol Biol Phys 2012; 82: 67-76.

124. Flieger M, Ganswindt U, Schwarz SB, Kreth FW, Tonn JC, la Fougere C, Ertl L, Linn J, Herrlinger U, Belka C, Niyazi $\mathrm{M}$. Re-irradiation and bevacizumab in recurrent high-grade glioma: an effective treatment option. J Neurooncol 2014; 117: 337-345.

125. Minniti G, Agolli L, Falco T, Scaringi C, Lanzetta G, Caporello P, Osti MF, Esposito V, Enrici RM. Hypofractionated stereotactic radiotherapy in combination with bevacizumab or fotemustine for patients with progressive malignant gliomas. J Neurooncol. 2015; 122:559-66.

126. Cabrera AR, Cuneo KC, Vredenburgh JJ, Sampson JH, Kirkpatrick JP. Stereotactic radiosurgery and bevacizumab for recurrent glioblastoma multiforme. J Natl Compr Canc Netw 2012; 10: 695-699.

127. Hundsberger T, Brugge D, Putora PM, Weder P, Weber J, Plasswilm L. Re-irradiation with and without bevacizumab as salvage therapy for recurrent or progressive high-grade gliomas. J Neurooncol 2013; 112: 133-139.

128. Rubenstein JL, Kim J, Ozawa T, Zhang M, Westphal M, Deen DF, Shuman MA. Anti-VEGF antibody treatment of glioblastoma prolongs survival but results in increased vascular cooption. Neoplasia 2000; 2: 306-314.

129. de Groot JF, Fuller G, Kumar AJ, Piao Y, Eterovic K, Ji Y, Conrad CA. Tumor invasion after treatment of glioblastoma with bevacizumab: radiographic and pathologic correlation in humans and mice. Neuro Oncol 2010; 12: 233-242.

130. Kunkel P, Ulbricht U, Bohlen P, Brockmann MA, Fillbrandt R, Stavrou D, Westphal M, Lamszus K. Inhibition of glioma angiogenesis and growth in vivo by systemic treatment with a monoclonal antibody against vascular endothelial growth factor receptor-2. Cancer research 2001; 61: 66246628.

131. Williams JR, Zhang Y, Zhou H, Gridley DS, Koch CJ, Slater JM, Little JB. Overview of radiosensitivity of human tumor cells to low-dose-rate irradiation. Int J Radiat Oncol Biol Phys 2008; 72: 909-917.

132. Bloch O, Safaee M, Sun MZ, Butowski NA, McDermott MW, Berger MS, Aghi MK, Parsa AT. Disseminated progression of glioblastoma after treatment with bevacizumab. Clin Neurol Neurosurg 2013; 115: 17951801.

133. Chamberlain MC. Radiographic patterns of relapse in glioblastoma. J Neurooncol 2011; 101: 319-323.

134. Shields LB, Kadner R, Vitaz TW, Spalding AC. Concurrent bevacizumab and temozolomide alter the patterns of failure in radiation treatment of glioblastoma multiforme. Radiat Oncol 2013; 8: 101.

135. Niyazi M, Jansen NL, Rottler M, Ganswindt U, Belka C. Recurrence pattern analysis after re-irradiation with bevacizumab in recurrent malignant glioma patients. Radiat Oncol 2014; 9: 299.

136. Gora-Kupilas K, Josko J. The neuroprotective function of vascular endothelial growth factor (VEGF). Folia Neuropathol 2005; 43: 31-39.

137. Joo KM, Jin J, Kang BG, Lee SJ, Kim KH, Yang H, Lee YA, Cho YJ, Im YS, Lee DS, Lim DH, Kim DH, Um HD, et al.. Trans-differentiation of neural stem cells: a therapeutic mechanism against the radiation induced brain damage. PloS one 2012; 7: e25936.

138. Kelly PJ, Dinkin MJ, Drappatz J, O'Regan KN, Weiss SE. Unexpected late radiation neurotoxicity following 
bevacizumab use: a case series. J Neurooncol 2011; 102: 485-490.

139. Bag AK, Kim H, Gao Y, Bolding M, Warren PP, FathallahShaykh HM, Gurler D, Markert JM, Fiveash J, Beasley TM, Khawaja A, Friedman GK, Chapman PR, et al.. Prolonged treatment with bevacizumab is associated with brain atrophy: a pilot study in patients with high-grade gliomas. J Neurooncol 2015; 122:585-93.

140. Kandalaft LE, Motz GT, Busch J, Coukos G. Angiogenesis and the tumor vasculature as antitumor immune modulators: the role of vascular endothelial growth factor and endothelin. Current topics in microbiology and immunology 2011; 344: 129-148.

141. Huang Y, Goel S, Duda DG, Fukumura D, Jain RK. Vascular normalization as an emerging strategy to enhance cancer immunotherapy. Cancer research 2013; 73: 2943 2948. 